\title{
Parent and Child Perceptions of Grade One Children's Out of School Play
}

\author{
Joanne Shari Lehrer and Hariclia Harriet Petrakos \\ Concordia University
}

\begin{abstract}
The transition from kindergarten to Grade 1 is marked by a sudden decrease in children's play time (Broström, 2005; Hartmann \& Rollett, 1994). This study sought to examine 69 Montreal-area Grade 1 children's beliefs about out of school play, as well as their parents' $(N=56)$ perceptions of their play. Findings indicate that parents value play for their child's development and education, for building relationships and self-esteem, for processing emotional experiences, for relaxation, and for fun. Many parents expressed a preference for active outdoor play, as well as pretend and creative play, board games, and puzzles, explaining that they discouraged television and video games, aggressive play, and play with sexual themes. Children reported enjoying active outdoor play, toys, construction and art activities, and video game play, with parents, siblings, friends, and pets. Limitations to play included lack of neighbourhood children, parents or siblings who did not play, and restrictions to inviting friends over.
\end{abstract}

The National Association for the Education of Young Children, a U.S. authority on early childhood education, defined early childhood as the period of time between birth and age 8, and asserted that play is fundamental to child development throughout this period (Bredekamp \& Copple, 2009). The Canadian Association for Young Children (2001), a similar Canadian organization, maintained that play is "essential in promoting children's healthy growth, development, and learning" (p. 2) and that children between 6 and 12 years need time, play partners, and appropriate materials and environments for 'quality play' in "home, community, school, and recreational settings" (p. 2).

Play has been linked to cognitive, socio-emotional development, as well as creativity, in early childhood (e.g., Bredekamp \& Copple, 2009; Ginsburg, 2007; Runco, 1996; Tsao, 2002). Previous research has identified links between creative arts and pretend play activity and social competence in preschool (Elias \& Berk, 2002; Kontos, Burchinal, Howes, Wisseh, \& Galinsky, 2002), and suggests that play in one environment can have a positive impact on behaviour in another (Hartmann \& Rollett, 1994). 
Preschool and kindergarten programs are often based on the premise of learning through play, but once children begin Grade 1, the amount of time spent playing in school declines dramatically (Broström, 2005; Hartmann \& Rollett, 1994; Patton \& Mercer, 1996; Yeom, 1998). Current international research on school transition supports the position that successful transition activities may include play opportunities for children to facilitate active learning and/or to support social and cognitive adaption to a potentially stressful experience (e.g., Broström, 2000; Corsaro \& Molinari, 2000; Fabian \& Dunlop, 2007). Play is also used to help children deal with their new role in school settings and to cope with the day-to-day structure and academic focus. For example, Mayo (2005) described how providing children with props, such as school uniforms and lunchboxes, during dramatic play can help them cope with the changes they experience as they transition from kindergarten to Grade 1. Broström (2005) described the transition to formal schooling as moving from an activity system of play to an activity system of school learning. He suggested that children often experience this transition as a culture shock that could lead to social and emotional turmoil, but that play can be used to ease the transition from one educational system to the next by occupying a central role in a 'transitory activity system.' Fisher (2009) noted that both teachers and parents are concerned about children not having enough time to play once they began formal schooling, and about the pronounced differences between the Foundation Stage and Key Stage 1 in England.

Previous research with Grade 1 teachers revealed that they differentiate between structured play and learning games used in the classroom and free play which takes place in after school care, at recess, or outside of school (Quance, Lehrer, \& Stathopoulos, 2008). Other studies have found that when school-age children are not permitted to play in the classroom they play at home, in after school care, at recess, in the car, while grocery shopping, and in any location where they have control over their use of time (De Lorimier, 1988; Hofferth \& Jankuniene, 2001).

Research on parental perspectives of children's play has been conducted only at the preschool level. This research has found that parents from different cultures and SES backgrounds varied in terms of the importance and developmental significance they assigned to children's play, and that parental beliefs about play were associated with how often, with whom, and which play activities children engaged in at home (e.g., Fantuzzo \& McWayne, 2002; Fogle \& Mendez, 2006; Galboda-Liyanage, Scott, \& Prince, 2003; Parmar, Harkness, \& Super, 2004; Tubbs, Roy, \& Burton, 2005). Research on child perspectives about play, on the other hand, has focused on children's differentiating between the concepts of work and play (Howard, 2002; King, 1979) and on the physical location of children's play (Burke, 2005).

There is a lack of research on play once children enter formal schooling. This includes a lack of investigation into parental perspectives about play and its role in children's transition to school. In addition, research on children's perspectives of play has been limited to differentiating between play and work in the classroom and on where children enjoy playing, but has not examined whom they play with, how they like to play, and how they feel about playing. As children begin formal schooling, the school environment may not be an ideal setting to study children's play. However, exploring children's play in different settings may provide some insight into how children are dealing with school transition and how their parents' perceptions of play and learning may impact their transition experiences.

The current study investigated parental and child beliefs about play at Grade 1 age in an effort to provide a more complete picture of the role of play in children's lives as they transition from kindergarten to Grade 1. Does play, as Broström suggested, act as a 'transitory activity sys- 
tem' that helps children cope with the transition to formal schooling? Given that their ability to play at school is limited to recess, after school care, and structured learning games in the classroom, how do parents and children view free play at home? Therefore, the purpose of this study is to describe parental and child beliefs about play at the Grade 1 level. A qualitative methodology was used to understand children's perspectives through drawings and open-ended interview questions. Parents were also asked to respond to open-ended questionnaire items that they completed on their own.

\section{Methodology}

\section{Participants and Setting}

Sixty-nine children in Grade 1 (42 boys, 27 girls) were recruited from suburban neighbourhoods near Montreal, and 56 of their parents (representing 38 boys, 18 girls) also took part in the study. These families were part of a larger 2-year longitudinal research project on children's transition to school. The children attended 19 different Grade 1 classes within seven different public schools in two English-language school boards and two different French elementary schools. The majority of the children attended French immersion programs $(81.3 \%)$, while the remainder attended English language (15.8\%) and French language programs (2.9\%). The majority of the children were born in the province of Quebec $(89.9 \%)$, while the remainder were born elsewhere in Canada, Europe, and Asia. Parents identified their children's ethnicity, with the most common classification being of European descent $(49.3 \%)$, followed by of mixed heritage (13\%). The majority of parents were born in Quebec $(60.9 \%$ mothers, $50.7 \%$ fathers $)$ and spoke English (40.6\% mothers, $47.8 \%$ fathers) or French (29\% mothers, $14.5 \%$ fathers) at home. About a third of the parents were university educated (40.5\% mothers, $30.4 \%$ fathers), and the majority of fathers $(60.9 \%)$ and almost half the mothers $(46.4 \%)$ reported working full-time.

The majority of children had either one $(34.8 \%)$ or two $(26.1 \%)$ siblings at home. Only five participants were only children (7.2\%). Two sets of twin boys (with one older sibling each) participated in the study. The majority of participants who shared this information had two parents who were either living together or apart, but who were both involved in the child's life $(65.2 \%)$. Seven parents reported that only one parent was involved in the child's life $(10.1 \%)$, four families reported living with grandparents as well as parents (5.8\%), and one family reported living with a number of disabled adults whom the parents cared for $(1.5 \%)$.

Teachers of 45 of the 69 children completed the Behavior Assessment System for Children-Second Edition, Teacher Rating Scale (Reynolds \& Kamphaus 2004). Ten of 45 of these children were identified as exhibiting atypical behaviours on at least one of the five subscales of the rating scale: externalizing problems, internalizing problems, behavioural symptoms, school problems, or adaptive skills.

\section{Measures}

Parent questionnaire. This questionnaire contains seven open-ended questions related to parental beliefs about their children's use of time and about play. The parents were asked the following questions:

1. Is there anything you would like to change, or wish you could change, about how your child spends his/her time after school? 
2. Is there anything you are particularly proud of or pleased with, when it comes to how your child spends his/her time?

3. What does your child enjoy doing most of the time after school? Does he/she have any favourite activities?

4. Do you think that play is important for your child at his/her present age? If yes, please explain how/why?

5. Are there particular types of play you encourage or support? Why?

6. Are there particular types of play you prohibit or discourage? Why?

7. Is there anything else you would like to add?

Child interview in pictures and words. Previous research has found that children use drawings as a language to express and communicate their thoughts, beliefs, and ideas (Einarsdottir, Dockett, \& Perry, 2009; Lodge, 2007; Trautner \& Milbrath, 2008). The children were interviewed at school by research assistants (including the primary author) in the context of the larger research project. The interview procedure was adapted from Petrakos' (2006) social support interview and involved the children drawing a picture about their out of school time ("draw what you like to do after school"). The children were provided with at least eight different colours of coloured pencils or markers and queried about whether they had enough time to do the things they liked; how they felt when they engaged in these activities; and about specific activities, such as playing indoors, playing outdoors, and doing homework, as well as who they liked to spend time with and where they liked to play. Research assistants noted the children's answers verbatim and transcribed the children's descriptions of their drawings. Children who did not talk about the picture while they were drawing were asked if they wanted to tell the research assistant about their drawing.

Demographic questionnaire. Parents filled out a questionnaire and provided data about the child's birthday; parent and child birthplaces; ethnic background; languages spoken at home; number, ages, and genders of siblings; number of parents and other adults at home; and parent employment and education.

\section{Procedure}

School boards, local school governing boards, families, and teachers provided consent for the study in the spring of 2006, while the children were attending kindergarten. Consent regarding participation in the sub-study was requested via an information letter to the parents. The parent questionnaires were sent home with the children in an envelope containing those and other forms as part of the larger study in the spring of 2008. Parents completed the questionnaires and returned them to their child's teachers between February and July 2008. The interviews with the children were conducted at school between January and May of 2008.

\section{Data Analysis}

Interview questions. The open-ended answers completed by parents $(n=55)$ were translated from French to English, where applicable, and all text was digitized into text documents. Preliminary coding was done as the data were being typed, using the computer program Stickies. Further coding and categorizing were completed using Hyperresearch qualitative data analysis software in an attempt to understand how parents view children's play at the Grade 1 
level, and to identify any factors that support or challenge the families' abilities to structure their after-school time.

Similarly, the child interview notes $(n=69)$ were translated, when necessary, and digitized before preliminary coding using Stickies. Further, more detailed coding and categorizing were done with Hyperresearch. The analysis focused on which activities children enjoyed, as well as where they liked to play and whom they liked to play with.

Children's drawings. The drawings were initially sorted into piles based on their content: the activities, number and relationship of people in picture, and the setting of the drawing. Then they were digitized into jpeg documents and analyzed using Hyperresearch. This more detailed analysis focused on the above criteria, as well as on elements of visual language, such as size and contour, choice of colour, and the placement of people and objects, examining the choices the children made in representing their favourite thing to do at home (Lodge, 2007; Trautner \& Milbrath, 2008).

Comparison of parent and child responses. A chart was created in Microsoft Excel comparing child self-reports of preferred out of school activities with parental reports of the same information. This chart was analyzed for patterns in similarities and differences between child and parental reporting and perception of the same information.

\section{Findings and Discussion}

\section{Parents' Perceptions of the Role of Play}

Although all the parents agreed that play is important for their child at his or her present age, they had very different ideas about the role of play activities in their children's lives. A number of parents echoed the curriculum documents and educational theory texts (Bennett, Wood, \& Rogers, 1997; Frost, Wortham, \& Reifel, 2005; Ministère de l'emploi, de la solidarité sociale et de la famille, 2004; Moyles, 2005; Murphy, 2006; Quebec Ministry of Education, 2001) by explaining the value of play for social, emotional, cognitive, physical, and creative development. However, others explained the value of play in building relationships, "it is a natural way for parents to bond with their child, as well as with other children/peers," enhancing confidence or self-esteem, building self-awareness or self-expression, and teaching children to respect differences, "culture, religion, and colour." Many parents saw play as a natural part of childhood and as being important simply because it is fun. One parent, who took great care to explain her weeknight routine and the importance of routine in her family, explained that play was important, "but on the weekends." While parents did not explicitly discuss the role of play in helping their children adapt to Grade 1, some claimed that play was important as it allowed the child to relax or "let out all excess energy." Unfortunately, the research methodology did not allow for further probing to find out if parents believed that these needs were related to the transition to school.

Parental play beliefs identified in this study were similar to findings reported in previous research with parents of preschool children (i.e., Farver \& Howes, 1993; Fogle \& Mendez, 2006; Haight, Parke, \& Black, 1997; Parmar et al., 2004; Tubbs et al., 2005). It is important to point out that not a single parent stated that their child had outgrown the need for play. 


\section{Parental Regulation of Children's Play}

Parents were asked directly whether there were forms of play they encouraged or discouraged with their children. The most common type of play parents encouraged was "active physical play to promote healthy lifestyle." Parents also expressed feeling good when their children engaged in creative and pretend play or when they assembled puzzles or played board games. A typical response was:

\section{Active play: physical play is part of healthy lifestyle. Creative play: she's good at it and expresses herself through this. Pretend play: it's a way to explore new avenues, it provokes questioning, it's a way to deal with her fears and evacuate the pressure.}

Some parents were particularly encouraging of outdoor play, without defining in detail the types of activities the children engage in outdoors. For example, "If it's nice outside, as a rule, he has to play outside." A few parents explained that they encourage the types of play that they themselves like to participate in with their child, "I encourage sports - to promote active lifestyle, puzzles, games - for academic (reasons), but mostly because these are things I like to play with them." Some parents expressed their support for their child's freedom in determining what and how they wanted to play: "free play, their time to initiate/direct their own activity."

By far the most common activity parents discouraged was "violent games" or "aggressive play," as one mother explained, "there is enough violence on T.V. and all around us, why promote the same via play time?" Some parents were also concerned about potential physical injury that could result from rough or dangerous play, "with four boys in the house, there has to be a limit to certain games." Other parents reported limiting television viewing, computer and videogame time, and explained, "video and computer games, no advantage at all" or "anti-social play. For me that is TV and video games."

The majority of the questionnaires were completed by mothers; only two fathers identified themselves as respondents. One of those fathers explained that he encouraged "roughhousing/wrestling" to help his daughter control aggression, but that he did not allow his daughter to wrestle with the neighbourhood children, as he was worried other parents would not permit such play.

A smaller number of parents also expressed concern with play that is mean-spirited, that may result in hurt feelings, or is simply impolite, "Anything that excludes people," "Teasing, hitting, although even these have educational benefit if learned from. We discourage these just on principle of being mean, naughty," and play that is not age appropriate, "J. likes to role play theatrically. I try to keep it at an innocent level. I discourage violence or play too sexy," or "Barbie Bratz type dolls - just don't like the look of Bratz, too provocative dress for young kids, no real point to those toys." It is possible that the greater amount of parental concern reported with regards to aggressive play may reflect the larger proportion of boys in the study.

These findings resonate with King's (1987) classification of elementary-aged children's play into instrumental, illicit, and recreational categories. While King's school-based research noted the encouragement and facilitation of instrumental play in the classroom, she found that teachers largely ignored recreational play, which took place only at recess, and actively discouraged and punished play they deemed illicit. In contrast, the parents in this study seem to encourage both instrumental and recreational play. This support for recreational play may be based on concerns for children's physical health and fitness or may be indicative of a dichotomy between the role of play in the classroom and the role of play during children's leisure time. 
The general agreement, particularly amongst mothers, about the types of play that are discouraged seems to echo the position of some post-modernist theorists (e.g., Canella, 1997; Edmiston, 2008; Jones, Hodson, \& Napier, 2005; Sutton-Smith, 1995,1997) that play is romanticized on the one hand - as the parents unanimously agreed that play was vital to their children's development - and used as a means of social control on the other. Canella (1997) argued that adults attempt to regulate and control children's play, suppressing activities they deem inappropriate, aggressive, or dangerous, and encouraging activities they consider productive, beneficial, or therapeutic. Sutton-Smith $(1995,1997)$ suggested that the notion of play as relating to children's progress and development is but part of the complete picture of the role of play in children's lives. While criticizing Western culture for attempting to sanitize, domesticate, and regulate children's play, he suggested that children's illicit play is an attempt at empowerment and emotional regulation, that children use play to make their present lives tolerable, and that they need unsupervised time in which to do so. Previous research has found this phenomenon to be true of early childhood educators as well. Hartmann and Brougère (2004) found that most educators exclude commercial toys, such as Barbie and action figures, from their classrooms, despite the fact that children report these as being their preferred play objects. Arthur (2005) found that early childhood educators were also likely to view television, video games, and computer games as having negative impacts on children's learning.

\section{Child Interviews}

Activities. In examining the answers children gave to questions about what they enjoy doing after school, patterns began to emerge with respect to different activities, as well as the social context of the activity. The activities children mentioned were categorized as active play, fantasy or pretend play, play with toys (i.e., dinosaurs or figurines), building with blocks or Lego, playing board games, art or drawing activities, media play (computer/video games/TV), and pet play. While some children mentioned a number of interests, such as watching television and "I do whatever I want, I play outside, or with my toys, I play with my family, play in the snow, go to the store," others seemed to focus on only one or two activities.

Some children had a difficult time recalling what they do after school, while others described elaborate play scenes such as, "This is me. After this the others were hiding, I found three, I still needed to find my brother. He played a joke on me. He was swimming and he hid under the water when I came to find him."

Children tended to draw and discuss activities that can be classified according to King's (1987) categories of recreational, instrumental, and illicit. They focused on television and video or computer games, pretend play, active outdoor play and sports, building, playing with toys, drawing, rough and tumble play, and playing with their pets. However, in contrast to school play, where illicit play seems fairly straightforward to identify, children's depictions and descriptions of television viewing, video game play, and wrestling with friends can only be classified as illicit play if their own parents prohibit or discourage such play. This play is unlikely to be viewed by parents as illicit for those who recounted playing video games with their fathers. Similarly, instrumental play in school is usually organized by a teacher and linked directly to academic or social outcomes. In the home context, pretend play, building with Lego, playing outside, drawing, and many other activities can be viewed as instrumental, but only if the child's parent(s) view(s) them as such. Other parents may view the same activities as recreational. However, most children answered "good" or "happy" when asked how they felt while engaged in their favourite 
activity. This seems to indicate that most play at home, at least from the child's perspective, could be classified as recreational, or at least enjoyable.

Social context. The vast majority of children mentioned friends as playmates, although a small number complained about their parents not allowing friends over, not allowing them to go to friends' houses, or that they did not play with friends very often outside of school, "my mom said mostly people don't come over to my house. I'm alone every time."

A little more than half of the children reported that they enjoyed playing with their parents, while the others stated that their parents did not play with them. For example, "They never play because my parents are too busy."

Of those children with siblings, many of them seemed to take playing with their sibling(s) for granted; for example, some children explained that they only play alone when their brother or sister is busy or annoying them. However, others reported that their siblings will not play with them or that they simply do not play with their siblings. Age differences and gender did not seem to fully explain whether a sibling was considered a playmate, as children with siblings close and further apart in age, and of the same and opposite sex, reported both joy and conflict in the sibling play relationship, as well as siblings who were not playmates.

Surprisingly, few children mentioned their extended family. Only 11 out of 69 children mentioned playing with or spending time with grandparents, uncles, and cousins. About half the children reported they liked playing alone, while the other half did not, "No, it's boring, there's nothing to do."

Play locations. When asked where they liked to play, children identified their homes, as well as particular locations in their home, such as "in my playroom" or "in my room and in the basement and on the sofa." Others identified outdoor locations such as "outside" in general, "my backyard," "the park," and "the pool." Many children reported that their favourite place to play was at "my friends' houses" in general or at the house of one particular friend. Three children responded that they liked to play "on the computer" or "on my PS2 (Play Station Two video game console)." One child referred specifically to his outdoor trampoline, one answered "wherever," and a few listed a number of locations, such as "backyard, at S.'s house (friend), all sorts of places." These findings are in contrast to those of Burke (2005) who found that 6- to 12-yearold children were more likely to identify outdoor space as play space, and in particular open spaces such as fields and school grounds. She also reported that children identified enclosed spaces as cozy, intimate, private play spaces. These spaces were located indoors, outdoors, and in the family car.

Play styles. Over 30 years ago, Wolf and Gardner (1979), in an analysis of young children's play, noted that children could be classified as either dramatists or patterners. Dramatists used objects to seek social exchanges and preferred symbolic play, while patterners were interested in the mechanical possibilities of objects and preferred constructive play. More recent research (i.e., Han, 2007; Park, 2005) has found that the majority of 3- to 5-year-old children can be classified as having mixed play styles (44 out of 58 and 20 out of 35 , respectively), as opposed to being identified as dramatists or patterners. However, the notion that children have distinct, and sometimes overlapping play styles, seems to emerge when examining this data for patterns between activity preference, social preference, and play location preference. Children who discussed playing outdoors often described active physical play, as well as either siblings or peers. Discussions of play inside the home, particularly play that could be classified as more 
calm or less active, such as play with toys or drawing/art, often involved either one sibling or the child alone. The majority of children who chose television or video games as their preferred activity often listed a number of other pleasurable activities, when probed. However, two boys reported that all they liked to do was play video games and that they did not like to spend time with anyone.

Opportunities for play. Discussions with the children revealed vast differences in the types of play opportunities they may have had outside of school. In addition to the presence or absence of siblings and the question of whether or not they played with their sibling(s) and parent(s), other activities, such as after school childcare and extracurricular classes, the availability of neighbourhood children to play with, and the ability to invite friends over, seem to help paint a picture of these children's social worlds beyond their schools. Some children explained that, "I don't play with neighbours "cause they're just grown-ups," while others were able to explain in great detail the fun they have on a regular basis with the children who live on their street. For example, "I play with my friend R. "cause he lives beside me and I always get to play with him on my road. I play like hockey and stuff like basketball, 'cause I have a basketball net on my road" or "There is this mud place all the kids like to go. We play in it. We made a trap once." While most children's faces lit up when asked if they like to play at friends' houses, a small number of children explained, "I can't invite friends 'cause my mom says no. I have to be older to invite friends."

Questions about pet play were not included in the Child Interview in Pictures and Words. However, children often mentioned, or drew pictures of, playing with their pet dogs and cats. A smaller number of parents also reported play with pets. Research on children and animals has tended to focus on animals used for therapeutic purposes in school or clinical counselling situations (e.g., Kaufmann, 1997; Parshall, 2003; Tilsen, 1998). Therefore, this finding is of some significance because it adds another activity to the list of types of play commonly engaged in by school-aged children.

Swimming, hockey, piano, dance, martial art, gymnastics, soccer, and scouts appear to be the most common organized activities the children participated in after school or on the weekend. The number of activities a child was likely to attend each week seemed to vary by school. In three of the four schools that the majority of children in the study attended, children were more likely to report attending one or no activities, while in the fourth school most children reported attending two or three activities each week. The majority of children in all four schools said they did not attend school-based childcare.

\section{Drawings}

Activities. When asked to draw a picture of their favourite thing to do after school, the vast majority of children $(n=57)$ drew themselves playing. Two children chose not to draw a picture, but described their favourite activity (playing video games in both instances) instead. The 67 drawings depicted active outdoor play (e.g., riding bikes, playing in the snow, playing hide and seek; $n=18)$, video game play on a console or computer $(n=14)$, play with toys $(n=$ 8 ), watching television programs or movies on television $(n=7)$, dramatic play $(n=5)$, pet play $(n=4)$, rough and tumble play $(n=2)$, homework $(n=2)$, drawing $(n=2)$, and helping parents by doing dishes $(n=1)$. Five children drew pictures of themselves with either a sibling or a friend, not obviously engaged in any activity. One child drew a picture of the lockers at school because, as she put it, "I like to do things at school only!" A few of the children split their pages 
in half by making a line through the centre of the paper and drew their two favourite activities. One child drew himself playing video games on one side of the page, drawing at a table on the other side, and his sister playing alone at the top of a set of stairs, while another drew himself playing with his toy garbage truck while watching TV (see Figures 1 to 3 for examples).

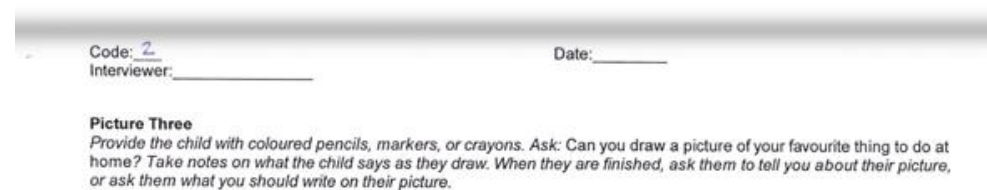

home? Take notes on what the child says as they draw. When they are finished, ask them to tell you about their pinture or ask them what you should wite on their picture.

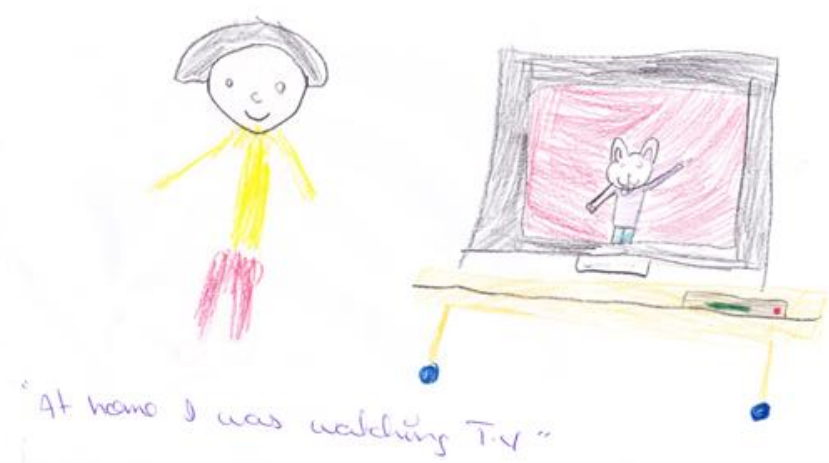

Figure 1. Drawing example one.

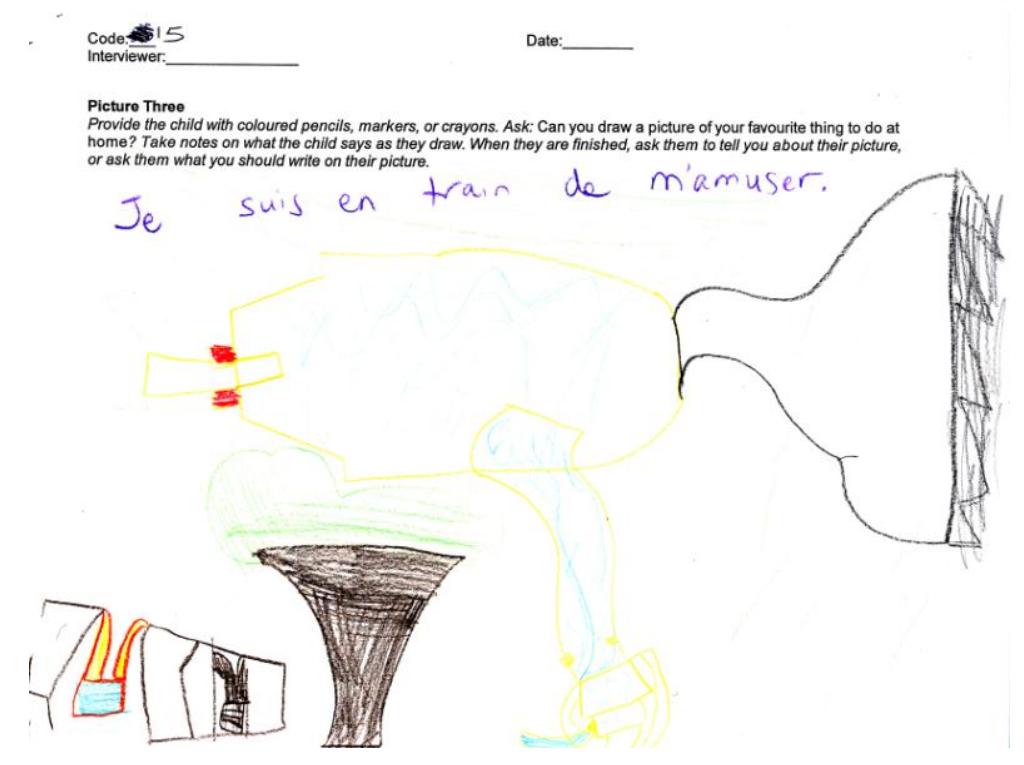

Figure 2. Drawing example two. 


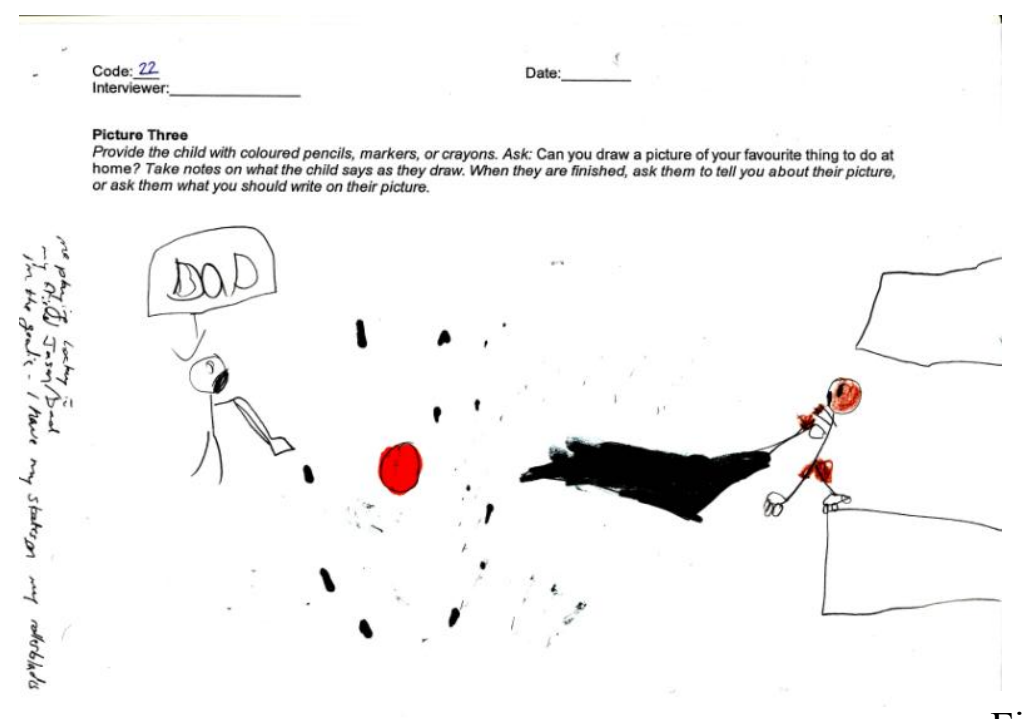

Figure 3. Drawing example three.

Social context. Children's drawings also differed with respect to the number and relationship of people in the picture. The majority of children drew themselves alone $(n=37)$, even though some of them, in describing their drawing, mentioned playing with someone else. Thirteen children drew themselves with one or more siblings, four children drew themselves with a parent, four children drew themselves with one friend, one child drew herself with three friends, and nine children drew an object (i.e., dollhouse, Lego construction, computer, trampoline) or outdoor scene that did not include any people. It is interesting to note that of the four drawings of parents, two were of children playing with their fathers (hockey and rough and tumble play), while the other two were of mothers, doing homework and washing dishes.

Physical setting. The drawings can be classified as objects and people floating in space $(n=22)$, including one or two elements that represent a physical setting to ground the subject matter (i.e., sun, piece of furniture, patch of grass; $n=37$ ), and elaborate drawings of scenes where the entire page is filled with a unified drawing $(n=9)$. Three children included a frontal view of their house, represented by a pentagon shaped object with doors, windows, and a chimney, that does not realistically depict the majority of houses in Montreal's suburbs, but obviously represents the child's home. The action in the drawing was represented through a window or in front of the house, but the house itself is the main feature of the drawings (see Figure 4).

Size and contour. The drawings ranged from simple stick figures to elaborate, detailed depictions of people and objects. Very few children made attempts at reproducing a threedimensional perspective, for example, by drawing objects in the background smaller than objects in the foreground or drawing a chair and table as one would view them from the side. The majority of children drew objects facing the viewer, but some included elements such as a line on the bottom of the page to represent grass or snow, or the mixture of bird's eye view perspective with forward-facing perspective, for example, by drawing a table as a rectangle with four legs sticking out or a ceiling fan as one would see if one were one to lie down on the floor, but placing a person standing next to it, facing the viewer (see Figure 5). According to current research on the subject, children begin to develop an awareness of spatial projects around age 7 , before that they draw what they know, not what they see (Lange-Küttner, 2008). There did not appear to be any relation between children's drawing complexity and their choice of subject matter. 


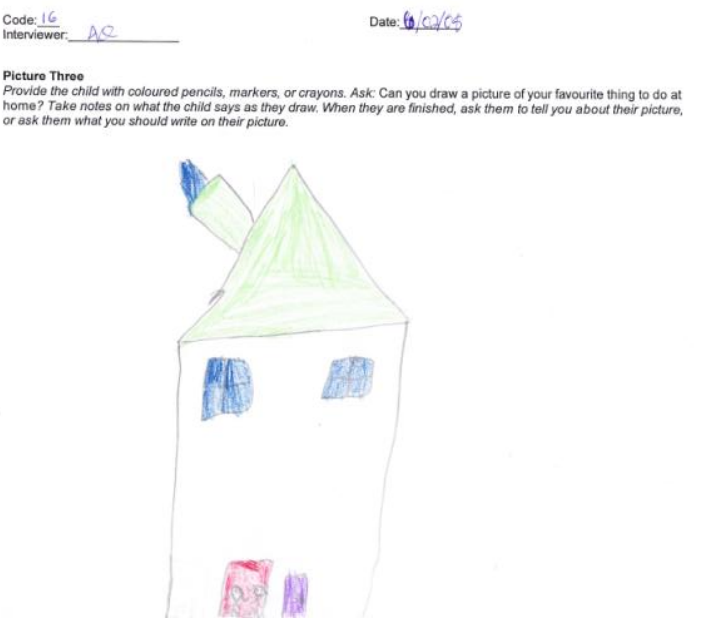

Figure 4. Drawing of house, "playing school with my sister."

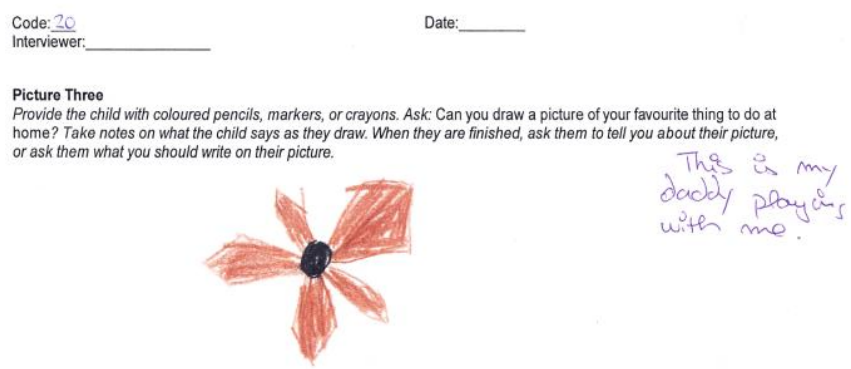

Figure 5. Drawing from multiple view-points.

Choice of colour. Children were provided with at least eight different colours of pencils or markers, and often up to 24 colour choices. Thirteen children drew monochromatic drawings, 6 children used two or three different colours, 46 used at least four colours, and 2 chose instead to use pencils, blue or black ballpoint pen, and pink or yellow highlighters. Children's use of colour in drawings appears to be related both to their own colour preferences as well as to the emotional response they have to the subject matter (Burkitt, 2008). No information was collected about children's favourite colours, but it is interesting to note that the most colourful pictures depicted outdoor play and pet play, as well as pictures of siblings and houses. 
In fact, all the outdoor play scenes, except one, used at least four different colours, as did all the pet play pictures. The monochromatic images often represented indoor play with toys, video games, the computer, and watching television, although a smaller number of drawings of these activities did use many colours. It is also important to note that girls' drawings often, but not always, included more colours than boys' drawings.

Placement of people and objects. All of the drawings that included one person were self-portraits. Of those drawings that included more than one person, the majority $(n=14)$ included two people, both facing forward and smiling. Usually the people were placed with some distance between them, ranging from a few millimetres to about 10 centimetres. Even those children who depicted people engaged in activities, such as cycling and washing dishes, where the bodies were positioned sideways, did not draw faces in profile, but facing the viewer (see Figure 6). One child drew four children, all of whom were facing forward in this way. Seven of the drawings depicted some relationship or interaction between people. This was achieved through an attempt to draw profile by giving each person only one eye, as if they were looking at one another $(n=5$; see Figure 7). Only two children drew people touching one another, and both drawings depicted rough and tumble play. One drawing, of a child pulling her younger brother on a sled, involved a series of ropes apparently attaching the two children. In comparison, two out of the four pet drawings included children touching a dog.

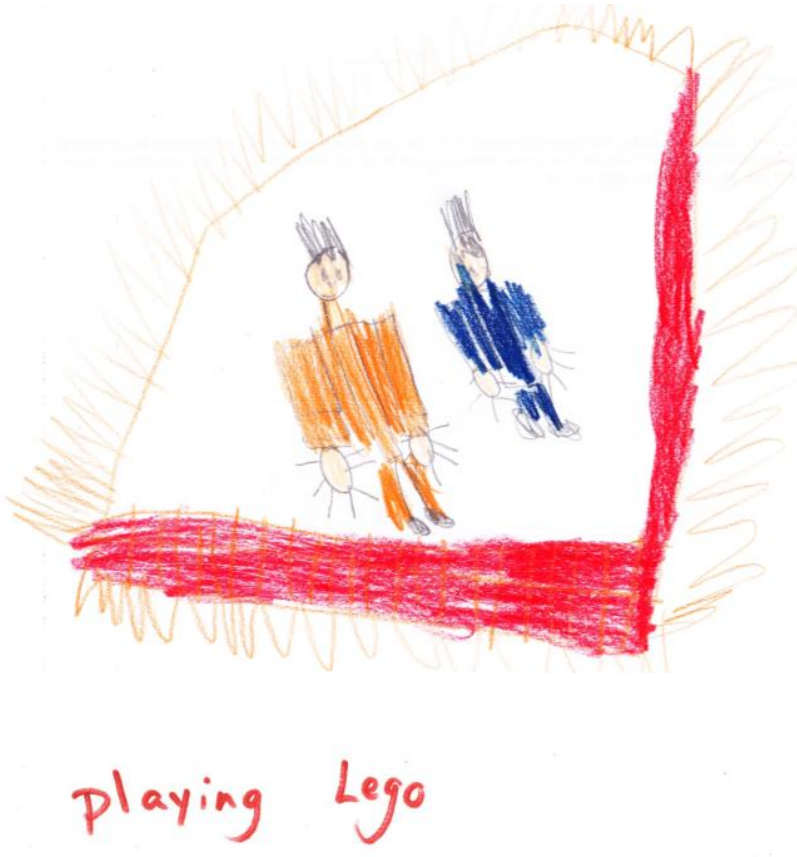

Figure 6. People facing forward.

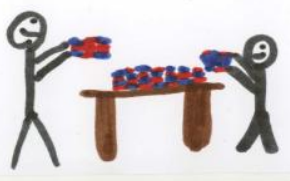

Figure 7. People facing each other. 
Children who drew themselves playing video games often portrayed the cord that attached the unit in the child's hand to the television set (see Figure 8). Drawings of children on the computer almost always positioned the child in front of the computer, with the back of his or her head facing the viewer. Drawings of children with their toys were most often drawings of children sitting next to their toy.

\section{Comparison of Parent and Child Perspectives of Play Preferences}

When examining parental and child perspectives of preferred play activities, it became apparent that a number of activities were reported more often by children, while others were mentioned more frequently by parents. For example, in response to the questions What does your child enjoy doing most of the time after school? Does he/she have any favourite activities? parents mentioned play and non-play activities, such as helping parents, eating snack, and following the daily routine, and structured activities such as karate class and attending after school childcare. Children, in answering a similar question about their favourite thing to do at home, also mentioned play activities and seemed more likely to report television, video games, and computer, as well as playing with their pet dog or cat.

In comparing the first three activities mentioned by each parent with the first three activities mentioned by their child, it is interesting to note that only 1 (of 52) parent-child pair mentioned all the same activities, 2 mentioned two activities in common, 16 mentioned one activity in common, and the majority of parents and their children mentioned a completely different set of activities $(n=33)$. Sometimes, it seemed possible that parents and children were labelling the same activities differently, for example, when a mother mentioned play with friends outside while the child stated that he enjoyed wrestling with his friend or when the parent wrote that the child liked Lego and the child explained that he played Lego video games on his computer. However, it is worth noting that parents seemed to report fewer of the activities they identified as problematic or that they limited, such as media use, particularly video games, as well as rough and tumble play. Almost half of both parents and children listed a social context, such as play with friends, siblings, parents, or alone, as favourite activities.
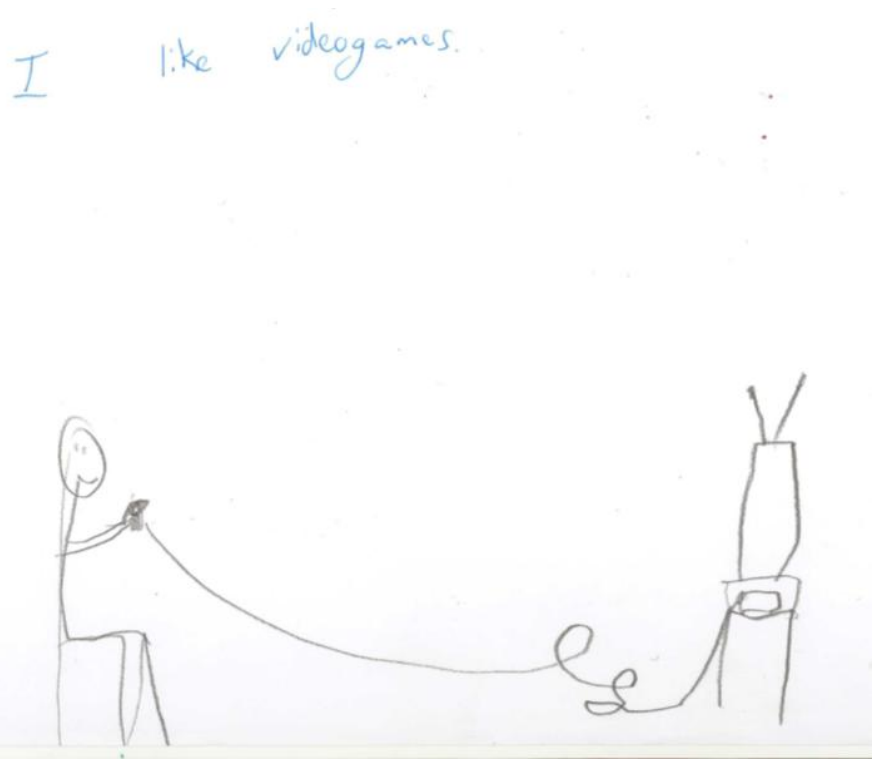

Figure 8. Videogame cord. 


\section{Conclusion}

The purpose of this study was to explore parent and child perspectives of children's out of school play in suburban Montreal as they transition to formal schooling. Both parents and children expressed that play is important and enjoyable for 6- and 7-year olds, although parents were more selective about which types of play they encouraged (active outdoor play, sports, pretend play, creative play, board games, puzzles) and restricted (television viewing and video games, violent or aggressive play, and play with sexual themes).

Different children and parents described different opportunities for play. Sometimes these opportunities were based on parental impositions, such as being forced to play outside on nice days or not being allowed to invite friends over. Other times, it appeared that these constraints were a matter of chance, or a result of other decisions, such as having friends to play with who lived nearby, the presence or absence of a sibling who was also a playmate, or being enrolled in many after school activities. Examining children's drawings, as well as the discrepancy between parental and child reports of preferred play activities, also allows for an understanding of the importance of the child's perspective in defining and interpreting play opportunities. It is possible that many children, including those who reported only engaging in video game play alone, expressed what is important to them and did not necessarily provide an objective depiction of how they spend their time. The children's perspectives of their after school play, regardless of the lack of congruence with their parents' perspectives, provide valuable insight into children's understanding of out of school play as they transition to school.

\section{Limitations of the Study}

Although this study adds a new perspective and important findings to the literature on children and play, a number of limitations need to be mentioned and kept in mind when planning future research. First, the data relied on individual interviews with children, children's drawings, and parent answers to open-ended questionnaire items. This data is somewhat superficial given the large number of participants and the relatively brief account provided by each participant. A more in-depth analysis would have been possible had more data been collected from fewer participants.

Second, there were more boys than girls in the sample, and this may have led to some conclusions that are more typical for boys than girls. More mothers than fathers completed the questionnaires, which may have further complicated the gender bias. In addition, the children in this study do not reflect all the multi-faceted diversity that one could find in the Greater Montreal Area. The majority of children in this study attended English language schools. It must be noted that in Quebec, only children whose parents have been educated in English, in Canada, have the right to attend English language schools; therefore, a more diverse sample of immigrant and refugee children were not represented in this study. In addition, the sample was drawn from suburban areas and the families were well educated and working outside the home. Therefore, the findings reflect the perceptions of only a small segment of the population.

Third, this study was carried out between January and May. The school year in Quebec runs from the end of August until the end of June. Although many argue that the transition process lasts at least two years (e.g., Entwisle \& Alexander, 1998; Fabian \& Dunlop, 2007), had the study been conducted during the months of September and October, it is possible that both parents and children would have shared more of their concerns related directly to beginning Grade 1. 


\section{Directions for Future Research}

Future research could examine the play beliefs and experiences of fathers in particular or of fathers as compared to mothers. It would also be interesting to investigate different family types, including the experiences of only children as compared to those with siblings or the role of birth order in children's play opportunities and preferences. Research could be conducted with older children to investigate how children's perceptions of play change as they age. Differences in play experiences and play locations, in urban, rural, and suburban settings, could also be examined. Research could investigate children's home play in more depth, perhaps including direct observation and/or video recording. Further research could also examine how choice is negotiated at home, and children's play with pets. Finally, the relationship between play at home and school-based outcomes, such as a successful transition to school, could be explored.

\section{Implications for Policy and Educational Practice}

For teachers, an understanding of parent and child beliefs about the value of play could be useful, either for making decisions about the inclusion of play at school or about the amount and type of homework they assign. For example, parent-child play, such as board games and other academically relevant play activities, could be assigned as homework.

In terms of educational policy, the discourse around play takes place only at the preschool level and focuses largely on the importance of play for early learning. This study suggests that older children's play needs to be prioritized as well, for example, by focusing on play opportunities in after-school care, the design of play spaces for 6- to 12-year-olds, and community safety measures to promote children's outdoor play opportunities. In addition, parent perspectives remind us that play's value is much greater than its relationship to helping children succeed in school.

\section{References}

Arthur, L. (2005). Popular culture: Views of parents and educators. In J. Marsh (Ed.), Popular culture, new media and digital literacy in early childhood (pp. 165-182). London: RoutledgeFalmer.

Bennett, N., Wood, E., \& Rogers, S. (1997). Teaching through play: Teachers' thinking and classroom practice. Philadelphia, PA: Teacher's University Press.

Bredekamp, S., \& Copple, C. (Eds.). (2009). Developmentally appropriate practice in early childhood programs (3rd ed.). Washington, DC: National Association for the Education of Young Children.

Broström, S. (2000, Aug.-Sept.). Transition to school. Paper related to poster symposium at the $10^{\text {th }}$ EECERA European Conference on Quality in Early Childhood Education, London, UK.

Broström, S. (2005). Transition problems and play as transitory activity. Australian Journal of Early Childhood, 30(3), 17-25. Retrieved from http://www.earlychildhoodaustralia.org.au/australian_journal_of early_childhood/about_ajec.html

Burke, C. (2005). "Play in focus:" Children researching their own spaces and places for play. Children, Youth, and Environments, 15(1), 27-53. Retrieved from http://www.colorado.edu/journals/cye/

Burkitt, E. (2008). Children's choice of color to depict metaphorical and affective information. In C. Milbrath \& H. M. Trautner (Eds.), Children's understanding and production of pictures, drawings, and art: Theoretical and empirical approaches (pp. 107-120). Cambridge, MA: Hogrefe.

Canadian Association for Young Children. (2001). Play for school age [Brochure].

Canella, G. S. (1997). Deconstructing early childhood education: Social justice and revolution. New York, NY: Peter Lang. 
Corsaro, W., \& Molinari, L. (2000). Priming events and Italian children's transition from preschool to elementary school: Representations and actions. Social Psychology Quarterly, 63, 16-33. doi:10.2307 12695878

De Lorimier, S. (1988). Pretend play in middle childhood: The effects of toy structure. (Unpublished master's thesis). Concordia University, Montreal, QC.

Edmiston, B. (2008). Forming ethical identities in early childhood play. New York, NY: Routledge.

Einarsdottir, J., Dockett, S., \& Perry, B. (2009). Making meaning: Children's perspectives expressed through drawings. Early Childhood Development and Care, 179(2), 217-232. doi:10.1080 /03004430802666999

Elias, C. L., \& Berk, L. E. (2002). Self-regulation in young children: Is there a role for sociodramatic play? Early Childhood Research Quarterly, 17, 216-238. doi:10.1016/S0885-2006(02)00146-1

Entwisle, D. R., \& Alexander, K. L. (1998). Facilitating the transition to first grade: The nature of transition and research on factors affecting it. Elementary School Journal, 98(4), 351-364. doi:10.1086/461901

Fabian, H., \& Dunlop, A. W. (Eds.). (2007). Informing transitions in the early years: Research, policy \& practice. Berkshire, UK: Open University Press.

Fantuzzo, J., \& McWayne, C. (2002). The relationship between peer-play interactions in the family context and dimensions of school readiness for low-income preschool children. Journal of Educational Psychology, 94(1), 79-87. doi:10.1037//0022-0663.94.1.79

Farver, J. M., \& Howes, C. (1993). Cultural differences in American and Mexican mother-child pretend play. Merrill-Palmer Quarterly, 39(3), 344-358. Retrieved from http://www.asu.edu/clas/ssfd/mpq/

Fisher, J. A. (2009). 'We used to play in Foundation it was more funner': Investigating feelings about transition from Foundation Stage to Year 1. Early Years, 19(2), 131-145. doi:10.1080 /09575140802672576

Fogle, L. M., \& Mendez, J. L. (2006). Assessing the play beliefs of African American mothers with preschool children. Early Childhood Research Quarterly, 21, 507-518. doi:10.1016/j.ecresq.2006.08.002

Frost, J. L., Wortham, S., \& Reifel, S. (2005). Play and child development. Upper Saddle River, NJ: Merrill Prentice-Hall.

Galboda-Liyanage, K. C., Scott, S., \& Prince, M. J. (2003). Time budgets of the mothers of pre-school children: An analysis of mother-child joint activities. British Journal of Developmental Psychology, 21(2), 273-283. doi:10.1348/026151003765264084

Ginsburg, K. R. (2007). The importance of play in promoting healthy child development and maintaining strong parent-child bonds. Pediatrics, 119, 182-191. doi:10.1542/peds.2006-2697

Haight,W. L., Parke, R. D., \& Black, J. E. (1997). Mothers' and fathers' beliefs about and spontaneous participation in their toddlers' pretend play. Merrill-Palmer Quarterly, 43(2), 271-290. Retrieved from http://www.asu.edu/clas/ssfd/mpq/

Han, M. (2007). Individual differences in play style and literacy: A bioecological perspective. In K. A. Roskos \& J. F. Christie (Eds.), Play and literacy in early childhood (pp. 119-132). New York, NY: Lawrence Erlbaum Associates.

Hartmann, W., \& Brougère, G. (2004). Toy culture in preschool education and children's toy preferences. In J. Goldstein, D. Buckingham, \& G. Brougère (Eds.), Toys, games, and media (pp. 37-54). Mahwah, NJ: Lawrence Erlbaum Associates.

Hartmann W., \& Rollett, B. (1994). Play: Positive intervention in the elementary school curriculum. In J. Hellendoorn, R. van der Kooij, \& B. Sutton-Smith (Eds.), Play and intervention (pp. 195-202). Albany, NY: State University of New York Press.

Hofferth, S. L., \& Jankuniene, Z. (2001). Life after school: From reading at home to playing sports at school, children's after-school lives vary according to such factors as gender, age, and parent's education levels. Educational Leadership, 58(7), 19-23. Retrieved from http://www.ascd.org/publications /educational-leadership.aspx

Howard, J. (2002). Eliciting young children's perspectives of play, work, and learning. Early Childhood Development and Care, 172, 489-502. doi:10.1080/03004430214548

Jones, L., Hodson, E., \& Napier, N. (2005). The politics of play. In L. Jones, R. Holmes, \& J. Powell (Eds.), Early childhood studies: A multiprofessional perspective (pp. 40-51). Berkshire, UK: Open University Press. 
Kaufmann, M. (1997). Creature comforts: Animal-assisted activities in education and therapy. Reaching Today's Youth: The Community Circle of Caring Journal, 1(2), 27-31. Retrieved from http://www.cycnet.org/Journals/rty.html

King, N. R (1979). Play: The kindergartener's perspective. Elementary School Journal, 80(2), 80-87. doi:10 $.1086 / 461176$

King, N. R. (1987). Elementary school play: Theory and research. In. J. H. Block \& N. R. King (Eds.), School play: A source book (pp. 143-166). New York, NY: Garland Publishing.

Kontos, S., Burchinal, M., Howes, C., Wisseh, S., \& Galinsky, E. (2002). An eco-behavioral approach to examining the contextual effects of early childhood classrooms. Early Childhood Research Quarterly, 17(2), 239-258. doi:10.1016/S0885-2006(02)00147-3

Lange-Küttner, C. (2008). Size and contour as crucial parameters in children drawing images. In C. Milbrath \& H. M. Trautner (Eds.), Children's understanding and production of pictures, drawings \& art (pp. 89106). Cambridge, MA: Hogrefe.

Lodge, C. (2007). Regarding learning: Children's drawings of learning in the classroom. Learning Environments Research, 10(2), 145-156. doi:10.1007/s10984-007-9027-y

Mayo, J. (2005). Passing on the baton. International Journal of Transitions in Childhood, 1, 46-51. Retrieved from http://extranet.edfac.unimelb.edu.au/LED/tec/journal_index.shtml

Ministère de l'emploi, de la solidarité sociale et de la famille. (2004). Un Québec Digne des enfants: Le plan d'action pour les enfants. Retrieved from http://www.mfacf.gouv.qc.ca

Moyles, J. (Ed.). (2005). The excellence of play. Berkshire, UK: Open University Press.

Murphy, B. (2006). Child centred practice in Irish infant classrooms: A case of imaginary play? International Journal of Early Childhood, 38(1), 112-124. doi:10.1007/BF03165981

Park, H. J. (2005). The relationship between teacher-perceived children's play styles and their pretend play behaviors (Unpublished doctoral thesis). University of Texas at Austin.

Parmar, P., Harkness, S., \& Super, C. M. (2004). Asian and Euro-American parents' ethnotheories of play and learning: Effects on preschool children's home routines and school behaviour. International Journal of Behavioral Development, 28(2), 97-104. doi:10.1080/01650250344000307

Parshall, D. P. (2003). Research and reflection: Animal-assisted therapy in mental health settings. Counseling and Values, 48(1), 47-56. Retrieved from http://www.counseling.org/publications/journals.aspx

Patton, M. M., \& Mercer, J. (1996). "Hey! Where's the toys?" Play and literacy in 1st grade. Childhood Education, 73(1), 10-13. Retrieved from http://www.tandf.co.uk/journals/journal.asp?issn=00094056\&linktype $=$ rates

Petrakos, H. (2006, July). The impact of family and school collaborative efforts on children's academic, social and behavioral functioning. Presented at the International Congress in Applied Psychology, Athens, Greece.

Quance, A., Lehrer, J. S., \& Stathopoulos, H. (2008). Play in the grade one classroom: An exploration of teacher beliefs, classroom organization, and obstacles to implementation in Quebec. Canadian Journal for New Scholars in Education, 1(1). Retrieved from http://www.cjnse-rcjce.ca/ojs2/index .php/cjnse

Quebec Ministry of Education. (2001). Quebec education program: Preschool education, primary education. Retrieved from http://www.mels.gouv.qc.ca

Reynolds, C. R., \& Kamphaus, R. W. (2004). Behavior Assessment System for Children: Second Edition. Bloomington, $\mathrm{MN}$ : Pearson Assessments.

Runco, M. A. (1996). The development of children's creativity. In B. Spodek \& O. N. Saracho (Eds.), Handbook of research on the education of young children (2nd ed., pp. 121-134). Mahwah, NJ: Lawrence Erlbaum.

Sutton-Smith, B. (1995). Does play prepare the future? In J. H. Goldstein (Ed.), Toys, play, and child development (pp. 130-146). New York, NY: Cambridge University Press.

Sutton-Smith, B. (1997). The ambiguity of play. Cambridge, MA: Harvard University Press.

Tilsen, J. (1998). Vignettes from the doghouse: Tales of canine co-therapy. Journal of Family Life: A Quarterly for Empowering Families, 4(4), 53-55. 
Trautner, H. M., \& Milbrath, C. (2008). Children's knowledge about pictures, drawing, and art. In C. Milbrath \& H. M. Trautner (Eds.), Children's understanding and production of pictures, drawings, and art: Theoretical and empirical approaches (pp. 3-18). Cambridge, MA: Hogrefe.

Tsao, L. L. (2002). How much do we know about the importance of play in child development? Review of research. Childhood Education, 78(4), 230-233. Retrieved from http://www.tandf.co.uk/journals /journal.asp?issn $=0009-4056 \&$ linktype $=$ rates

Tubbs, C. Y., Roy, K. M., \& Burton, L. M. (2005). Family ties: Constructing family time in low-income families. Family Process, 44(1), 77-91. doi:10.1111/j.1545-5300.2005.00043.x

Wolf, D., \& Gardner, H. (1979). Style and sequence in early symbolic play. In M. Franklin \& N. Smith (Eds.), Symbolic functioning in childhood (pp. 117-138). Hillsdale, NJ: Lawrence Erlbaum.

Yeom, J. S. (1998). Children's transition experiences from kindergarten to grade one. Canadian Children, 23(1), 25-33. Retrieved from http://www.cayc.ca/Journal.html

\section{Authors' Note}

Correspondence concerning this article should be addressed to Joanne S. Lehrer, Université de Québec à Montréal, Case postale 8888, succursale Centre-Ville Montréal (Québec), H3C 3P8. Email: lehrer.joanne@courrier.uqam.ca

This study was part of the primary author's Master's thesis project, entitled, Out of school play of grade one students: child and parent perceptions and their relation to academic outcomes (Lehrer, 2009), and supported by SSHRC and FQRSC grants. That project was part of a larger 2-year longitudinal research project on children's transition to school, entitled, A two-year study of the psycho-social and contextual factors associated with children's early transition to school (Petrakos, 2005-2009), supported by the SSHRC. Preliminary findings were presented at the Canadian Society for Studies in Education Conference in June, 2008. 